\title{
Respiratory Complications of Organophosphorus Nerve Agent and Insecticide Poisoning Implications for Respiratory and Critical Care
}

\author{
Elspeth J. Hulse ${ }^{1,2}$, James O. J. Davies ${ }^{2,3}$, A. John Simpson ${ }^{4}$, Alfred M. Sciuto ${ }^{5}$, and Michael Eddleston ${ }^{1,2}$ \\ ${ }^{1}$ Pharmacology, Toxicology, and Therapeutics, University/BHF Centre for Cardiovascular Science, University of Edinburgh, Edinburgh, \\ United Kingdom; ${ }^{2}$ South Asian Clinical Toxicology Research Collaboration, University of Peradeniya, Peradeniya, Sri Lanka; ${ }^{3}$ Weatherall \\ Institute of Molecular Medicine, Oxford University, Oxford, United Kingdom; ${ }^{4}$ Institute of Cellular Medicine, Newcastle University, \\ Newcastle, United Kingdom; and ${ }^{5}$ Analytical Toxicology Division, U.S. Army Medical Research Institute of Chemical Defense, Aberdeen \\ Proving Ground, Aberdeen, Maryland
}

\begin{abstract}
Organophosphorus (OP) compound poisoning is a major global public health problem. Acute OP insecticide self-poisoning kills over 200,000 people every year, the majority from self-harm in rural Asia. Highly toxic OP nerve agents (e.g., sarin) are a significant current terrorist threat, as shown by attacks in Damascus during 2013. These anticholinesterase compounds are classically considered to cause an acute cholinergic syndrome with decreased consciousness, respiratory failure, and, in the case of insecticides, a delayed intermediate syndrome that requires prolonged ventilation. Acute respiratory failure, by central and peripheral mechanisms, is the
\end{abstract}

primary cause of death in most cases. However, preclinical and clinical research over the last two decades has indicated a more complex picture of respiratory complications after OP insecticide poisoning, including onset of delayed neuromuscular junction dysfunction during the cholinergic syndrome, aspiration causing pneumonia and acute respiratory distress syndrome, and the involvement of solvents in OP toxicity. The treatment of OP poisoning has not changed over the last 50 years. However, a better understanding of the multiple respiratory complications of OP poisoning offers additional therapeutic opportunities.

Keywords: organophosphorus; insecticide; nerve agent; critical care
Poisoning with organophosphorus (OP) compounds after accidental or deliberate exposure is a major global problem. In 1990, the World Health Organization (WHO) estimated that 20,000 people died annually from accidental pesticide poisoning and that 200,000 died from self-poisoning (1). A recent systematic review (2) and a subsequent large Indian study (3) suggest that pesticide self-poisoning kills around 350,000 people every year. Of all pesticides, OP insecticides (Figure 1A) are most important, being responsible for around two thirds of deaths and several million nonfatal cases annually $(2,4)$.

Less common, but more lethal, are weaponized OP compounds (Figure 1B). These OP nerve agents include the $G$ series compounds developed in Germany (tabun [GA], sarin [GB], and soman [GD]), VX developed in the United Kingdom, and the Novichok agents designed by the Soviets. The devastating effects of exposure to these compounds has been graphically demonstrated in Damascus, Syria (sarin in 2013) (5), in Halabja, Iraq (sarin, tabun,
VX, and mustard in 1988), and to a lesser extent in Matsumoto (sarin in 1994) and Tokyo (sarin in 1995) (6). Some commercially available insecticides (e.g., phorate, rat oral $\mathrm{LD}_{50} 1 \mathrm{mg} / \mathrm{kg}$ ) have animal toxicities that are similar to those of nerve agents (e.g., sarin, rat oral $\mathrm{LD}_{50}$ $0.5-1 \mathrm{mg} / \mathrm{kg}$ ) and are therefore considered a potential terrorist threat.

Although the usual methods of absorption differ between weaponized (topical, inhalational) and self-harm (ingestion, topical) OP exposures, the

(Received in original form June 24, 2014; accepted in final form October 21, 2014)

Supported by Wellcome Trust grants 063560, 085979, and 090886.

Author Contributions: E.J.H. and J.O.J.D. wrote the first drafts of this paper, and M.E. extensively edited the paper. All authors worked on multiple drafts of this paper; all saw and approved the final manuscript.

Correspondence and requests for reprints should be addressed to Michael Eddleston, Sc.D., Pharmacology, Toxicology, and Therapeutics, Queen's Medical Research Institute E3.20, 47 Little France Crescent, Edinburgh EH16 4TJ, UK. E-mail: m.eddleston@ed.ac.uk

CME will be available for this article at www.atsjournals.org

This article has an online supplement, which is accessible from this issue's table of contents at www.atsjournals.org

Am J Respir Crit Care Med Vol 190, Iss 12, pp 1342-1354, Dec 15, 2014

Copyright $\odot 2014$ by the American Thoracic Society

Originally Published in Press as DOI: 10.1164/rccm.201406-1150Cl on November 24, 2014

Internet address: www.atsjournals.org 
A

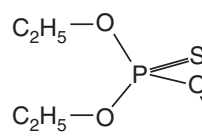

Diethyl group

e.g., Parathion

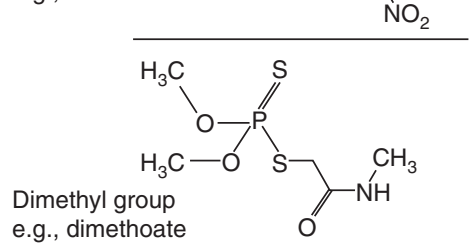

e.g., dimethoate

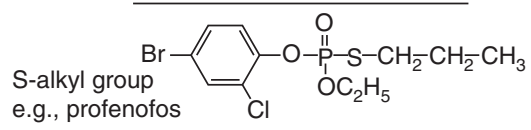

B

Sarin

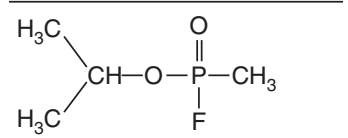

VX

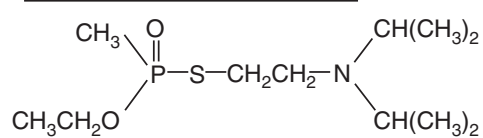

Figure 1. Structures of organophosphorus $(\mathrm{OP})$ insecticides and chemical weapons. $(A)$ Structures of the diethyl, dimethyl, and S-alkyl OP insecticides parathion, dimethoate, and profenofos, respectively. The great majority of insecticides are either dimethyl or diethyl; inhibition of acetylcholinesterase produces a diethylated or dimethylated phosphate atom that does not vary according to the individual $\mathrm{OP}$ involved. Both parathion and dimethoate are "thion" pro-poisons that require activation by cytochrome P450s to active "oxons" that have the $\mathrm{P}=\mathrm{O}$ group. Profenofos exists as an oxon and does not require activation. $(B)$ Structures of the OP nerve agents sarin and VX.

chemical structure, effects, and treatment of both sets of compounds are comparable $(6,7)$.

\section{Pharmacology}

OP compounds inhibit esterase enzymes, in particular acetylcholinesterase (AChE) and butyrylcholinesterase (BuChE) (8). AChE breaks down acetylcholine at cholinergic synapses, curtailing activity (9). Inhibition results in excessive acetylcholine and cholinergic overstimulation within the peripheral, central, and autonomic (both parasympathetic and sympathetic) nervous systems and tissues. Inhibited AChE may reactivate spontaneously, reactivate more quickly with the aid of an oxime drug (e.g., pralidoxime), or become irreversibly bound to the OP, a process known as "aging" (10).
Although multiple other enzymes are inhibited by OP compounds (e.g., BuChE), the clinical significance of their inhibition is unclear (11). An AChE knockout mouse showed identical clinical features and increased sensitivity during VX poisoning compared with wild-type mice (12), suggesting the involvement of other mechanisms of OP toxicity.

Clinical data are not available for all aspects of OP poisoning. Therefore, this review includes animal data. However, studies have shown marked species differences in OP pharmacokinetics/ dynamics and response to treatment. Primate and porcine (13) models are currently considered the most clinically relevant animal models, and therefore data from these species are presented preferentially.

\section{Acute Clinical Presentation}

People exposed to nerve agents commonly report a pungent odor that is quickly followed by headache, dyspnea, nausea, eye pain, and in severe cases collapse (14). Patients ingesting OP insecticides often give off a strong chemical smell from their breath and clothes.

The acute cholinergic crisis creates a toxidrome of muscarinic (miosis, hypersalivation, nausea, emesis, bronchospasm, bronchorrhea, alveolar edema, bradycardia, and hypotension) and nicotinic (sweating, muscle weakness, fasciculations, and paralysis, occasionally with hypertension and tachycardia) features (8). A combination of pin-point pupils, sweating, and fasciculations is pathognomic of OP poisoning. Although it is unclear whether the central features of unconsciousness, seizures, and respiratory depression are predominantly muscarinic or nicotinic in origin, they contribute to respiratory failure and complications (Figure 2) $(14,15)$.

\section{Deaths from OP Poisoning}

Most deaths after OP poisoning occur acutely due to the hypoxia created by the combination of peripheral acute cholinergic effects and central apnea, made worse by seizures (particularly with OP nerve agents). Other deaths occur later from cardiovascular distributive shock, neuromuscular junction (NMJ)

dysfunction, recurrent cholinergic toxicity, or complications of reduced consciousness and respiratory failure. Speed of poisoning onset, which affects whether a person survives to healthcare contact after severe poisoning, varies according to the compound and to the route of exposure, with the quickest being inhalation, then ingestion, and then topical.

In the Tokyo nerve agent attack, severely poisoned patients exposed by inhalation quickly became unconscious and developed marked respiratory compromise, some with cardiopulmonary arrest (14). Likewise, loss of consciousness and respiratory distress occurred within minutes of accidental inhalation and topical exposure of the nerve agents sarin and soman (16). Toxicity is delayed after topical nerve agent exposure but can occur within minutes with the most potent nerve agents (6).

The case fatality for OP nerve agents depends on the degree of exposure, largely governed by the proximity to the released agent (gas or liquid vapor). After the Tokyo subway sarin attack, over 5,000 people presented for medical assessment. Eleven patients died at the scene. The nearest large hospital received 640 patients; 112 showed signs of moderate to severe poisoning. Only four patients required intubation and ventilation for cardiorespiratory arrest. Two died in hospital: one from a cardiac arrest on admission and the other 28 days later from hypoxic brain damage (14).

Ingestion of insecticides can also produce rapid onset of poisoning, with reports of a death within 5 minutes from mevinphos (17) and need for intubation and ventilation within 15 to 30 minutes of poisoning by parathion (18). Many people poisoned by highly toxic insecticides die in the community before presentation to hospital, often due to a lack of adequate transport. However, patients poisoned by relatively less toxic WHO Class II thion insecticides, such as chlorpyrifos, generally do not require intubation and ventilation until 2 to 4 hours after exposure. Recurrent cholinergic toxicity and respiratory failure may also occur much later for highly fat-soluble thion OP insecticides such as fenthion (19). This variation is due to chemical differences in the insecticides that determine their pharmacokinetics and dynamics, need for and speed of activation 
by gut wall and liver cytochrome P450s, inhibitory potency, and speed of AChE inhibition (20).

Of the patients who survive to hospital over $25 \%$ of cases require intubation and ventilation, depending on the OP involved (see Table E1 in the online supplement). This causes intense resource issues in rural Asian district hospitals (where most patients present) because there are often inadequate numbers of trained doctors, ventilators, and intensive care beds (21). The overall in-patient case fatality of OP is usually between 10 and $20 \%$ (2) but may reach $50 \%$ in patients who require intubation (Table E1).

\section{Patterns of Respiratory Complications}

Respiratory complications of OP poisoning occur during, and as a consequence of, the acute cholinergic crisis, delayed neuromuscular dysfunction, and recurrent cholinergic toxicity (Table 1). In a large Sri Lankan case series of proven OP insecticide exposure, there were two commonly observed patterns of respiratory failure: (1) respiratory failure requiring early intubation within 2 hours of exposure in unconscious patients during the acute cholinergic crisis $58 \%$ of intubated patients) and (2) respiratory failure occurring later (often more than $24 \mathrm{~h}$ after exposure) in conscious patients without cholinergic signs (32\%) (19) (see Figure E1). Patients who were intubated after 24 hours required a significantly longer period of ventilation.

This division between early respiratory failure in unconscious patients and later respiratory failure in conscious patients with isolated NMJ dysfunction, first reported by Wadia and colleagues (22), was also seen in a small cohort studied using electrophysiology. Patients intubated within 24 hours $(n=7)$ were found to have a median Glasgow coma score of 10/15 (range, 4-13) and normal peripheral nerve/muscle electrophysiology at intubation (phrenic nerve/diaphragm those intubated after 24 hours $(n=5)$ had a median Glasgow coma score of 15/15 (range, 12-15) and grossly abnormal peripheral nerve/muscle electrophysiology, indicating severe disruption of

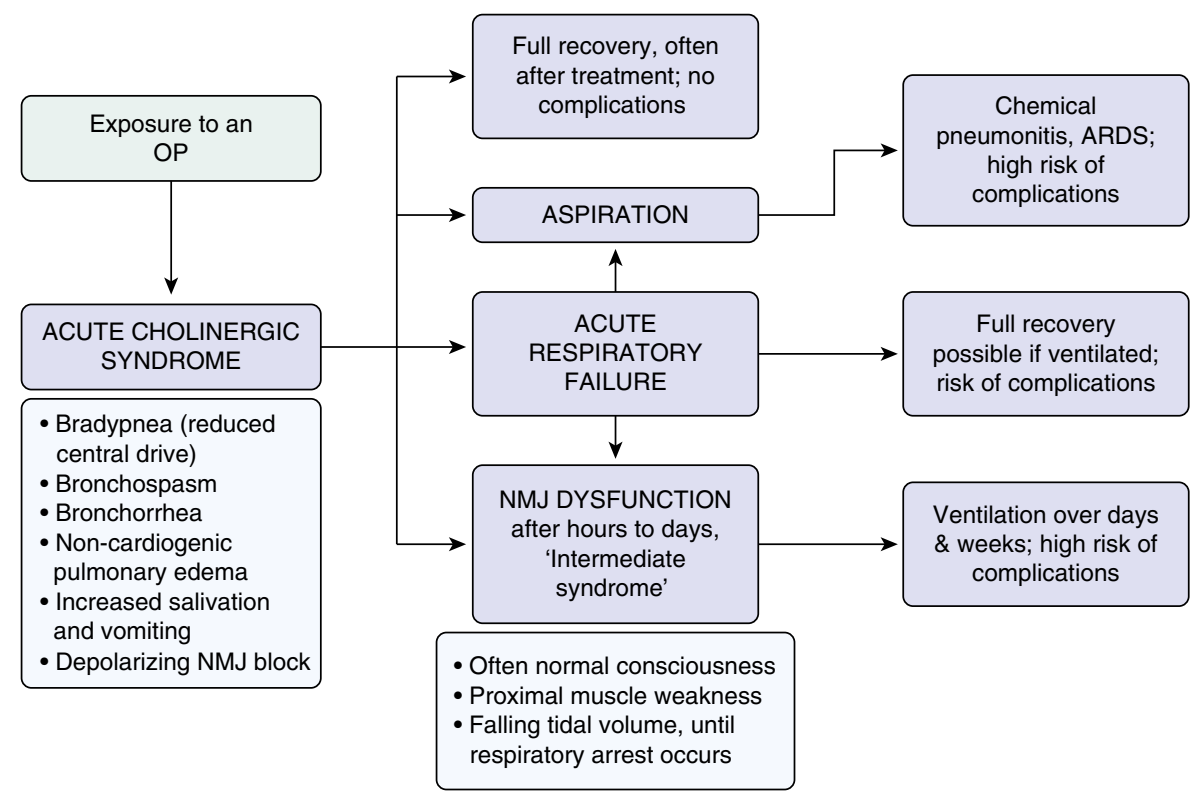

Figure 2. Respiratory system toxicity secondary to organophosphorus (OP) poisoning. $A R D S=$ acute respiratory distress syndrome; NMJ = neuromuscular junction function was not tested). In contrast, neuromuscular transmission (23).

\section{Acute Cholinergic Syndrome}

During the acute cholinergic crisis, respiratory failure can occur from local pulmonary muscarinic effects (e.g., bronchoconstriction, bronchorrhea, and alveolar edema), central depression of the respiratory center, and a flaccid paralysis through depolarizing block of the muscles of respiration $(8,24,25)$. Studies across several animal species indicate that the relative importance of the different mechanisms varies by species. The exact balance of the three mechanisms in causing death in humans is uncertain; however, central

Table 1. Respiratory Complications of Organophosphorus Poisoning
Acute cholinergic syndrome

Complications of the acute cholinergic syndrome

Intermediate effects of OP poisoning

Delayed effects of OP poisoning respiratory failure predominates in nonhuman primates (see below), suggesting that this is likely to be the dominant mechanism in humans.

\section{Local Airway Effects}

Animal studies show that OP compounds cause bronchospasm, most likely due to local effects $(26,27)$. Bronchial smooth muscle predominantly contracts in response to muscarinic M3 receptor stimulation, with some involvement of nicotinic and $\mathrm{M} 2$ receptors (the latter also demonstrate negative feedback control [28]). The nonspecific muscarinic
Local airway effects ARDS

Central nervous system effects Neuromuscular junction effects Aspiration pneumonitis and pneumonia

Complications of ventilation Immunomodulation

Neuromuscular junction dysfunction and intermediate syndrome

Delayed or recurrent cholinergic toxicity

Overlapping acute and intermediate poisoning effects

OP-induced delayed polyneuropathy Delayed pulmonary sequelae
Alveolar fluid and bronchorrhea

Definition of abbreviations: ARDS = acute respiratory distress syndrome; OP = organophosphorus 
antagonist atropine is highly effective at reversing bronchorrhea and bronchoconstriction.

\section{Alveolar Fluid and Bronchorrhea}

Alveolar fluid has been observed in many cases of OP insecticide poisoning (Table E1). In the biggest published autopsy case series of 85 patients with OP insecticide poisoning (treated with adequate doses of atropine: 12-24 mg every hour, up to $1 \mathrm{~g} / 24 \mathrm{~h}$ ), $75 \%$ of patients dying within 24 hours $(n=36)$ showed pulmonary interstitial edema, and $25 \%$ showed parenchymal hemorrhage (29).

Bronchorrhea results from neuronal and nonneuronal cholinergic stimulation of the mucus glands, cilia, and cells producing periciliary fluid $(30,31)$. Although atropine turns off excess fluid production, it does not increase the removal of fluid from the alveolus via the interstitial space and lymphatics (31). Fluid removal therefore limits the rate of improvement in oxygenation after atropine therapy. Sympathetic stimulation may help remove fluid from the alveoli through $\beta$ receptor activation (32). However, the effect of salbutamol in OP-poisoned guinea pigs was transitory, suggesting involvement of other mechanisms (27). A series of animal and clinical studies is needed to improve our understanding of the central and/or local pathophysiology of alveolar edema after OP poisoning (33) because its resolution could correlate with patient survival in acute lung injury (34).

Animal studies show disruption of the pulmonary endothelial-epithelial barrier by blood-borne OP compounds. Intravenous $\mathrm{VX}$ given to open chest anesthetized dogs caused alveolar edema secondary to an increase in pulmonary capillary permeability (35) and similarly in ex vivo rabbit lung perfusion studies using intravenous parathion (36). In vivo pig studies using oral dimethoate EC40 (E.J. Hulse and M. Eddleston, unpublished data) and rabbit studies using oral fenthion (37) have shown disruption of the endothelial-epithelial barrier. Aspirated dimethoate can also cause direct and indirect disruption of alveoli (Figure 3) (38). Human studies are lacking.

\section{Acute Respiratory Distress Syndrome}

Acute respiratory distress syndrome

(ARDS) has been reported in several cases of OP insecticide poisoning (Table E1) (39).
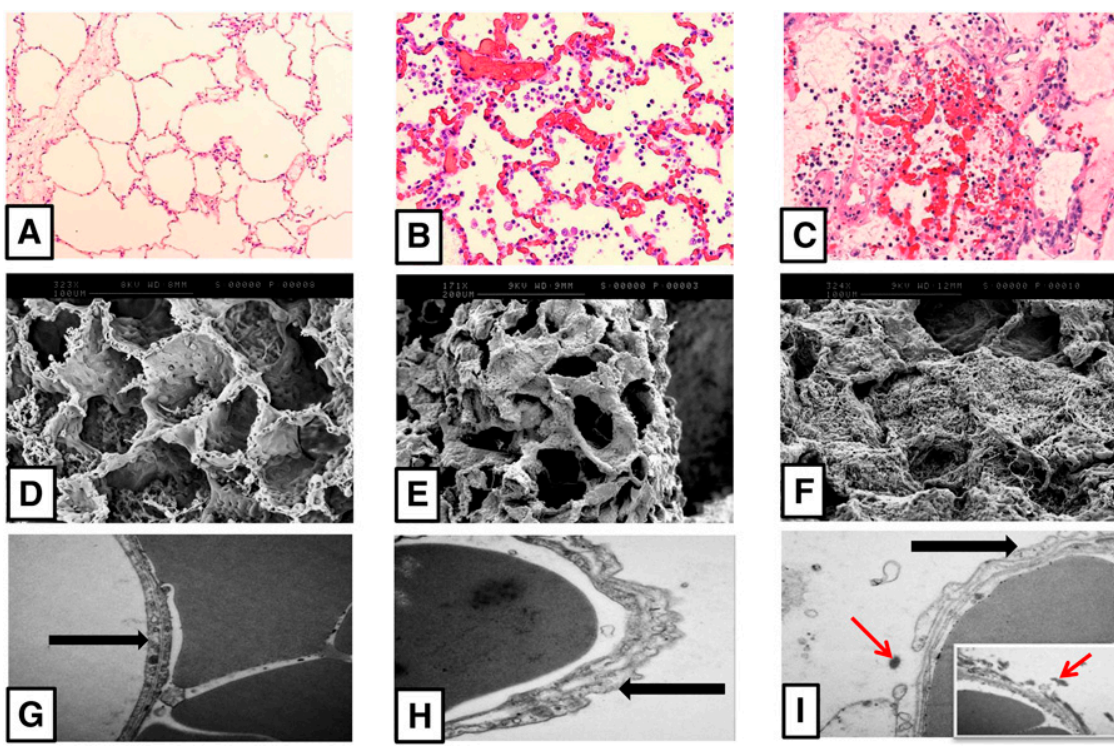

Figure 3. Effects of hematogenous organophosphorus $(\mathrm{OP})$ and aspirated $\mathrm{OP}$ on minipig lung Comparison of lung architecture in anesthetized minipigs 48 hours after administration of saline into the lung (control pig; $A, D$, and $G$ ), gastric contents and the agricultural $\mathrm{OP}$ insecticide dimethoate EC40 into the contralateral lung (indirect hematogenous injury; $B, E$, and $H$ ), and gastric contents and agricultural $\mathrm{OP}$ insecticide dimethoate $\mathrm{EC} 40$ into the right lung (direct injury; $C, F, 1$ ). (A-C) Light microscopy images (original magnification: $\times 10-20$ ) with hematoxylin and eosin. Compared with indirect injury, direct injury caused greater alveolar and interstitial edema, neutrophil infiltration, hemorrhage, fibrin deposition, vascular congestion, and necrosis. Images edited in PowerPoint. $(D-F)$ Scanning electron microscopy images (original magnification: $\times 171-324)$ of the same lungs. Direct injury shows extensive destruction of the alveolar capillary framework, with fibrin mesh and clot formation. (G-l) Transmission electron microscopy images (original magnification: $\times 25,000$ ) of the same lungs. Both indirect and direct injury cause alveolar capillary membrane swelling. The black arrow signifies the alveolar capillary membrane in control $(G)$ and indirect $(H)$ lungs. After direct injury, this has led to the alveolar epithelium peeling away into the alveolar space and fibrin deposition (red arrow) in and around the alveolar capillary membrane.

It may result directly from pulmonary complications of poisoning, such as aspiration or inhalation, or indirectly via hematogenous exposure to OP compounds. Because ARDS may be undiagnosed in over $50 \%$ of nonpoisoning cases (40), it seems likely that it is frequently undiagnosed in OP-poisoned patients.

Guinea pigs and rats exposed by inhalation to VX, soman, or sarin develop ARDS as shown by a dose-dependent increase in alveolar fluid, substantial increases in bronchoalveolar lavage protein and neutrophils, and alveolar hemorrhage and inflammation (41-43). Primates exposed to sarin by inhalation also develop a pulmonary neutrophilia (44).

\section{Central Effects}

Clinical experience of rapid respiratory arrest with nerve agents and potent insecticides suggests that the predominant early mechanism in humans is likely to be central. In the absence of clinical studies of OP-induced acute clinical respiratory arrest, animal models have been used to look at this effect. Central respiratory depression can be measured and distinguished from NMJ dysfunction by recording phrenic nerve activity and the diaphragm's response to phrenic nerve stimulation (45).

In nonhuman primates, lethal sarin and soman vapor dosing caused apnea, hypoxia $\left(\mathrm{Pa}_{\mathrm{O}_{2}}<50 \mathrm{~mm} \mathrm{Hg}\right)$, and phrenic nerve signal failure within 5 minutes (44). Diaphragm NMJ function (pressure generation by bilateral phrenic nerve stimulation) was 70 to $80 \%$ of normal in sarin-poisoned animals and normal in soman-poisoned animals. This indicated that central effects seemed to predominate at the time of respiratory arrest.

Diaphragmatic NMJ function did deteriorate over the following hours, returning to $>70 \%$ of baseline by Day 4 . Phrenic nerves studies have been done in OP-poisoned patients (46), but they were 
performed to study the intermediate syndrome within 48 hours of poisoning and did not look at acute cholinergic respiratory failure. Phrenic nerve neurophysiology/ diaphragm electromyography clinical studies are required during the acute cholinergic syndrome-induced respiratory failure to determine whether central or NMJ dysfunction predominates in human poisoning.

The mechanism of OP-induced central respiratory depression is unknown. The proposed respiratory center pacemaker-the Pre-Boetzinger complex-in the venterolateral medulla has glutamatergic and muscarinic control. Excess acetylcholine may alter the function of the the Pre-Boetzinger complex or other linked hindbrain areas to depress respiratory activity $(47,48)$. Pretreatment with centrally acting (but not peripherally acting) anticholinergic drugs protected against respiratory failure in rat models of OP poisoning, suggesting central muscarinic control (49). A more in-depth review of CNS failure secondary to $\mathrm{OP}$ poisoning can be found elsewhere (33).

OP nerve agents, and to a lesser extent insecticides, can cause seizures (excitatory activity), thereby worsening cerebral hypoxia and already compromised respiratory efforts. Seizures have been reported after severe sarin poisoning and have been documented by the United Nations investigation team in $19 \%$ of a group of survivors $(n=36)$ from Damascus after the sarin attacks (5). Diazepam prevented central respiratory depression in OP-poisoned rats, perhaps by reducing seizure-like activity, allowing normal respiratory center signaling (50).

The mechanism of CNS toxicity may also occur through CNS inflammation. Animal models have shown that glial cell activation occurs after exposure to nerve agents, with release of chemokines and cytokines in areas of the brain responsible for respiratory control (51).

\section{NMJ Effects}

During the acute cholinergic crisis, an excess of acetylcholine at NMJs can lead to fasciculations and a flaccid paralysis due to a depolarizing block. In his original description of NMJ dysfunction, Wadia and colleagues noted fasciculations and paralytic signs in 27 and $26 \%$ of patients, respectively, after diazinon insecticide poisoning (22). A case series noted that fasciculations and paralysis at the start of poisoning were associated with an increased occurrence of intermediate syndrome (see below) (52). Moderate to severe sarin toxicity in humans during the Tokyo subway attack produced fasciculations and muscle weakness in 20 to $35 \%(\mathrm{n}=111)$ of patients $(14)$.

\section{Complications of the Acute Cholinergic Syndrome}

The pulmonary complications of the cholinergic syndrome are presented in Figure 4 .

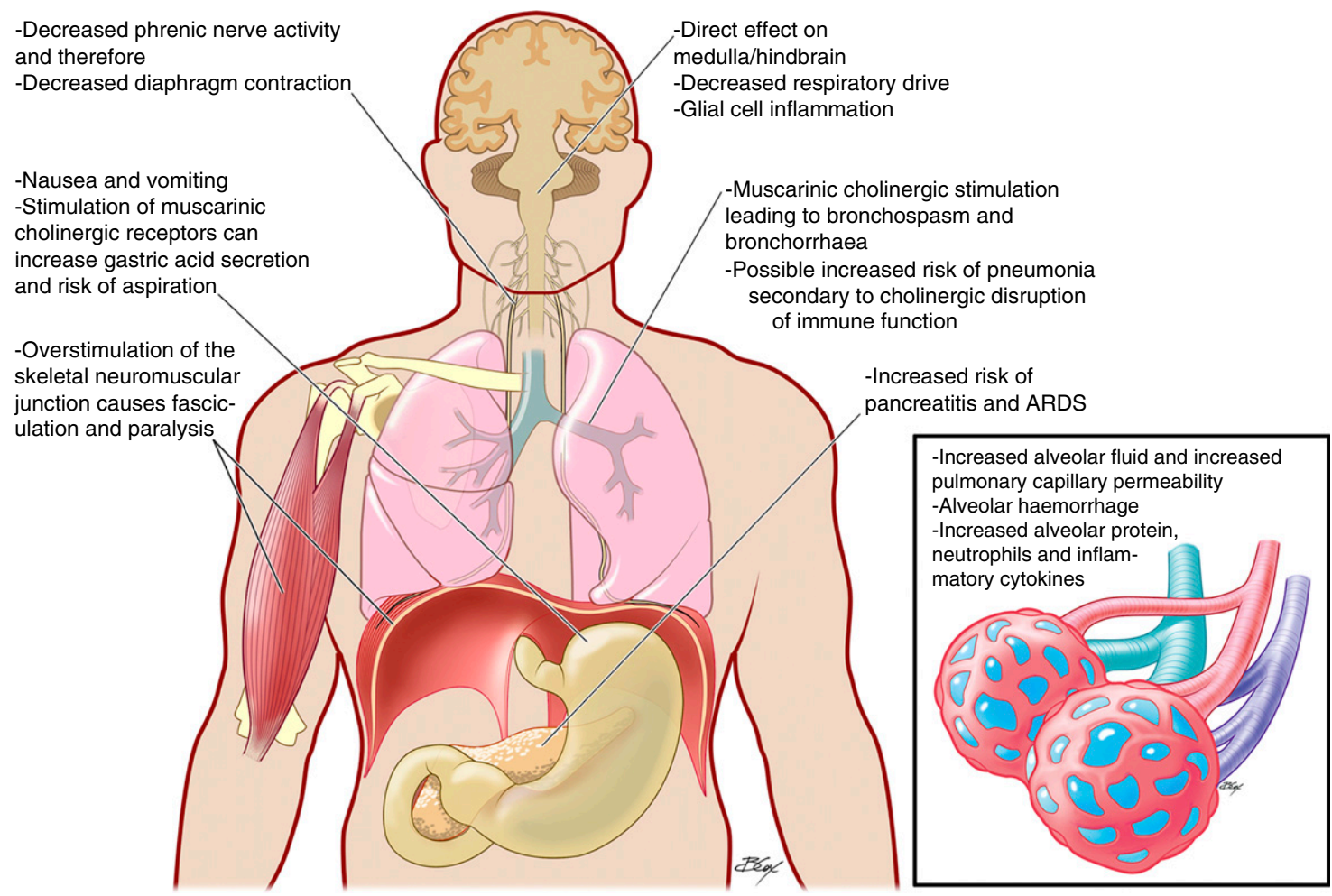

Figure 4. Pulmonary complications of organophosphorus (OP) poisoning. Exposure to OP compounds causes the acute cholinergic syndrome characterized by reduction in central respiratory drive, bronchospasm and hypoxia due to bronchorrhea and alveolar edema, and depolarizing neuromuscular junction (NMJ) block. This may resolve or progress to acute respiratory failure that would be fatal without medical input. Reduced consciousness and loss of airway control in the cholinergic syndrome increases the risk of aspiration, resulting in chemical pneumonitis that will worsen oxygenation and may progress to ARDS. Overstimulation of the NMJ causes chronic peripheral dysfunction that may occur simultaneously with the acute cholinergic syndrome or after it has resolved with normal cerebral function (then termed the "intermediate syndrome"). This NMJ dysfunction often requires days and weeks of mechanical ventilation with associated risk of ventilator-associated pneumonia and barotrauma. 


\section{Aspiration Pneumonitis and Pneumonia}

Clinical case series suggest that as many as $30 \%$ of OP insecticide-poisoned patients aspirate (Table E1). In an autopsy case series of 85 patients with OP insecticide poisoning, over two thirds of the 49 patients who died after 24 hours showed segmental or lobar consolidation, likely due to aspiration (29). This finding is not confined to resource-poor intensive care units (ICUs); aspiration pneumonia was reported in $82 \%(27 / 33)$ of OP insecticide-poisoned patients admitted to a German ICU (53).

OPs cause vomiting, increased secretions, loss of consciousness, and loss of airway protection, with or without seizures. When these features occur before hospital presentation, aspiration is common. Patients can also aspirate after gastric lavage or forced emesis (54). Aspiration in the context of selfpoisoning increases length of hospital stay, morbidity, case fatality (55), and cost of health service.

Animal studies show that gastric acid secretion is increased through cholinergic stimulation of M3 and M5 receptors and through inhibition of somatostatin release from $\mathrm{D}$ cells (56, $57)$. The presence of low-pH $(<2.5)$, high-volume $(>0.3 \mathrm{ml} / \mathrm{kg})$ food particles and bacteria with proinflammatory cells increases the risk of severe lung injury after aspiration due to any cause $(58,59)$. Normal gastric contents aspiration is estimated to cause $20 \%$ of ICU ARDS cases $(60)$, with case fatality as high as 40 to $50 \%(61)$.

Up to a third of OP insecticidepoisoned patients (Table E1) may develop pneumonia as a result of prehospital aspiration, unsafe gastric lavage, or ventilation.

\section{Complications of Ventilation}

Ventilation for acute cholinergic poisoning or NMJ dysfunction leaves patients at risk of complications, such as ventilatorassociated pneumonia (VAP) (62) and ventilator-induced lung injury (63). Although the incidence of these complications in OP-poisoned patients is unknown, adherence to modern VAP prevention strategies (64-66) and best ICU practice could contribute to reduced morbidity for these patients.

\section{Immunomodulation}

Lung inflammation is modified by the cholinergic nervous system in murine models, with cholinergic activation producing a broadly anti-inflammatory pulmonary effect (67). These observations have been made using "sterile" models of inflammation (e.g., using LPS- or acid-induced inflammation) similar to aspiration. In murine models, the effect appears to be mediated by the macrophage $\alpha 7$ nicotinic acetylcholine receptor $(\alpha 7 \mathrm{nAChR})$; its stimulation reduces damage caused by pulmonary inflammation induced by sterile stimuli (68). No primate or porcine studies have been published.

However, this effect in the face of infection may be harmful because $\alpha 7 \mathrm{nAChR}$ stimulation in rodent pneumonia is associated with decreased neutrophil accumulation and slower clearance of bacteria (69). Stimulation of $\alpha 7 \mathrm{nAChR}$ on neutrophils ex vivo leads to impaired superoxide generation and bacterial killing (70). Rats chronically exposed to subcutaneous VX and sarin or nicotine showed a decrease in metabolic and phagocytic neutrophil activity, combined with a reduction in TNF- $\alpha$, IL-1 $\beta$, and IL- 6 . The authors conclude that this was largely due to cholinergic stimulation of $\alpha 7 \mathrm{nAChR}$ within the monocyte phagocytic system (71).

The human lung is extensively innervated by the parasympathetic nervous system (72). If cholinergic immunosuppression also occurs in humans, OP poisoning should cause such effects. No clinical studies have been performed in poisoned patients; however, a study of Polish factory workers producing OP insecticides showed an increased incidence of upper respiratory infections and reduced in vitro neutrophil function compared with control subjects (73). Clinical research is needed to determine how cholinergic effects on inflammation affect outcome in OPpoisoned patients.

\section{Intermediate Effects of OP Compound Poisoning}

\section{NMJ Dysfunction and the Intermediate Syndrome}

The cholinergic crisis is often followed by paralysis of proximal muscles that particularly affects the muscles of respiration. This paralysis may occur after resolution of cholinergic features and is termed "Type II paralysis" (22) or "intermediate syndrome" (74).

In the 1970 s original case series, NMJ paralysis occurred in $18 \%(36 / 200)$ of diazinon OP insecticide-poisoned patients (22); a second large, prospective, observational cohort study found a similar proportion of patients with NMJ paralysis (31/176 [18\%]) (75). Respiratory failure frequently lasts for more than 1 week. In a case series of patients with laboratory-proven $\mathrm{OP}$ insecticide poisoning who were intubated more than 24 hours after exposure, the median time to final extubation was 219 hours (interquartile range, 154-276 h) (19). This prolonged ventilation leaves patients at risk of common serious complications.

As classically defined (74), the intermediate syndrome occurs 24 to 96 hours after OP insecticide exposure and consists of weakness or paralysis of the respiratory muscles, proximal limb muscles, neck flexors, and motor cranial nerves in the absence of cholinergic symptoms. Its incidence varies according to the OP involved and the severity of poisoning; dimethyl OP insecticides, such as methylparathion and fenthion, are commonly responsible, but it does occur with diethyl OP insecticides, such as parathion (76). Among a case series of patients poisoned by WHO Class II insecticides fenthion, chlorpyrifos, and dimethoate, only fenthion-poisoned patients were commonly intubated for the first time after 24 hours (Figure E1).

A recent detailed clinical study of 78 OP insecticide (mostly chlorpyrifos)poisoned patients showed 10 patients with progressive changes in their response to repetitive nerve stimulation that correlated with the severity of intermediate syndrome (77). Five patients developed respiratory failure; four of them showed severe and characteristic decrement effects before respiratory arrest. Thirty patients developed a forme fruste manifestation of the intermediate syndrome with less severe weakness not progressing to respiratory failure; their repetitive nerve stimulation showed modest change but no severe decrement. This study revealed that the intermediate syndrome shows a spectrum of NMJ dysfunction and that characteristic changes in repetitive nerve stimulation can 
identify a subgroup of patients at high risk of developing respiratory failure (77).

Intermediate syndrome is not thought to occur after OP nerve agent poisoning (78). However, one person severely poisoned in the Matsumoto sarin attack experienced tongue fasciculation for 14 days and had absent airway and deep tendon reflexes for 5 days (79).

NMJ dysfunction is proposed to occur due to overstimulation of nicotinic receptors at the synapse resulting in downregulation of receptors $(74,76)$. It is typically unresponsive to atropine and oximes $(22,80)$. Recent work suggests that NMJ dysfunction after poisoning with agricultural dimethoate formulations is due to a combination of metabolites of the active ingredient (omethoate) and solvent (cyclohexanol) (81).

\section{Critical IIIness Polyneuropathy/ Myopathy}

The incidence of critical care polyneuropathy with OP poisoning is unknown and may be hard to distinguish from the intermediate syndrome. No cases have been reported in the literature.

Some clinicians propose that intermediate syndrome occurs due to skeletal myopathy (52). Muscle necrosis at the motor end plate has been observed in animals after exposure to OP insecticide and nerve agents (78) and at the diaphragm after human parathion poisoning (82). Raised creatine kinase levels have been observed in OP-poisoned patients (52), but the role of extended bed rest or seizure activity was not excluded. Evidence thus far does not suggest that muscle necrosis is important in the development of respiratory failure attributable to $\mathrm{OP}$ poisoning.

\section{Delayed or Recurrent Cholinergic Toxicity}

Very fat-soluble OP insecticides, such as dichlofenthion (83) and fenthion (20), cause delayed onset cholinergic poisoning, usually more than 24 to 48 hours after exposure. They can also cause recurrent cholinergic features days to weeks after poisoning, perhaps as fat stores are metabolized and OP is released. In a case series of five dichlofenthion-poisoned patients, one apparently stable patient developed sudden fatal cholinergic respiratory toxicity 60 hours after exposure, a second patient decompensated after 40 hours and needed resuscitation, and a third patient required atropine for 47 days to prevent recurrent cholinergic toxicity (83). Such recurrent effects are likely to explain the delayed encephalopathy and coma reported 4 to 7 days after admission for a small case series of patients poisoned by fat-soluble OP insecticides (84).

\section{Overlap of Acute Cholinergic Toxicity and NMJ Dysfunction/Intermediate Syndrome}

Classically, the intermediate syndrome occurs after resolution of the acute cholinergic crisis (22). However, cholinergic symptoms and NMJ dysfunction sufficient to require long-term ventilation (i.e., the intermediate syndrome) are not mutually exclusive and may overlap $(19,22,52)$. In the large case series of Sri Lankan patients requiring intubation, some dimethoatepoisoned patients regained consciousness as the acute cholinergic syndrome settled yet were paralyzed and continued to require ventilation for days and weeks. In these patients, there was clear overlap between cholinergic features and intermediate syndrome-like NMJ dysfunction (19).

\section{Delayed Effects of OP Poisoning}

\section{OP-induced Delayed Polyneuropathy}

OP insecticide poisoning may be followed weeks later by an OP-induced delayed polyneuropathy due to inhibition of neuropathy target esterase in axons $(85,86)$. Neuropathy target esterase catalyzes the deacylation of phosphatidylcholine-the major phospholipid of eukaryotic cell membranes-to soluble products. Its inhibition causes paralysis, with swelling and degeneration of distal long axons in the legs and spinal cord. OP-induced delayed polyneuropathy can cause respiratory failure through phrenic nerve involvement (87).

Around 40 severely poisoned patients were re-examined 3 weeks after the Matasumoto Japanese sarin attack. Of these, $30 \%$ were experiencing dysesthesia of the extremities, with $15 \%$ experiencing dysphagia and paresis of perioral muscles. One person had a persisting peripheral neuropathy 1 year later (88).

\section{Delayed Pulmonary Sequelae}

Follow-up of patients exposed to only nonblistering nerve agent attacks during the Iran-Iraq war in the 1980s showed long-term pulmonary sequelae. In 201 survivors ( $>80 \%$ life-long nonsmokers), $11 \%$ had abnormal spirometry, with $58 \%$ having an abnormal chest CT, most commonly showing air trapping and emphysematous changes (89). It is unclear whether similar chronic lung damage occurs after ingestion and/or aspiration of an OP insecticide.

\section{Importance of Solvents and Surfactants}

OP poisoning may be worsened by the coingestion of the coformulated compounds, such as solvents (e.g., cyclohexanone, xylene, or petroleum fractions). Porcine studies indicate that cardiovascular toxicity, reduced consciousness, and NMJ dysfunction after exposure to agricultural dimethoate formulations are due to both the dimethoate active ingredient and the solvent (81). Aspiration of both solvents and surfactants, as well as gastric contents and $\mathrm{OP}$, may exacerbate pulmonary damage (90).

\section{Management of OP Nerve Agent and Insecticide Poisoning}

Management requires urgent resuscitation with oxygen and careful fluid management plus the intravenous administration of doubling doses of atropine to patients with cholinergic features (in particular: pinpoint pupils, excess sweating, bronchorrhea, bradycardia, hypotension, and dyspnea) (91). If oxygen is unavailable, atropine can be given in its absence during resuscitation (92) (Table 2).

The amount of atropine required can be large; in one case series, the dose of atropine required for resuscitation varied from 1 to $75 \mathrm{mg}$ (mean, $23 \mathrm{mg}$ ) (93). Once atropinization has been obtained, an infusion should be set up and titrated against effect. This doubling-dose approach has been shown in a randomized controlled trial to markedly speed resuscitation (from a mean of 152 to $24 \mathrm{~min}$ ) and reduce mortality (from 22.5 to $8 \%$ ) compared with 
Table 2. Clinical Management of Organophosphorus-poisoned Patients

Intervention

Maintain airway and provide adequate oxygenation ( $>85 \%$ saturations)

Administer escalating dose atropine regimen

Administer benzodiazepines

Administer oximes

Ventilation strategy

Cardiovascular instability

Prevention of VAP

Inhaled $\beta$-agonists, anticholinergics

Prevention of CIP/CIM

ICU sedation

\section{Comment}

Quick and efficient securing of the airway. Note: the depolarizing neuromuscular blocker suxamethonium will have a prolonged effect (up to $12 \mathrm{~h}$ ) due to acetylcholinesterase inhibition. Avoid where possible $(25,112,113)$.

Give intravenous atropine (initially $0.6-3 \mathrm{mg}$, doubling every $5 \mathrm{~min}$ until muscarinic features start to subside). This will help maintain patient oxygenation and lessen the risk of aspiration injury. Infusions of atropine may be required for many days; titrate to effect $(93,94)$. Do not delay if oxygen is not immediately available (92).

Give diazepam 10-20 mg or lorazepam 2-4 mg to control seizure activity and agitation, and to sedate intubated patients.

Give $1 \mathrm{~g}$ pralidoxime or $250 \mathrm{mg}$ obidoxime, then an infusion. Oximes are not of proven clinical benefit but can be considered in patients presenting early. Patients should be weaned when possible, preferably guided by neurophysiological studies.

Use protective ventilation $(6 \mathrm{ml} / \mathrm{kg})$; avoid plateau pressures $>30 \mathrm{~cm} \mathrm{H}_{2} \mathrm{O}$.

Response to NDMRs may be unpredictable $(25,114)$. Titrate dose to effect.

Use of aminosteroid NMBAs (e.g., rocuronium) may provide some protection of nicotinic receptors.

Dysrhythmias and severe hypotension can occur in OP poisoning and are treated by standard ICU practices (53). Note: effects of drugs that are metabolized by plasma cholinesterase (BuChE) (e.g. esmolol, may prolonged in OP poisoning).

Provide VAP prevention strategies: sit the patient at $30-45^{\circ}$, consider selective digestive and/or oropharyngeal decontamination (66), start antibiotics (after consultation with a local microbiologist) only if bronchopneumonia or sepsis is suspected (64).

Standard therapy for many critical care units. Observe for tachyarrhythmias when combined with intravenous atropine.

Wean as early as possible from the ventilator to reduce the risk of CIP/CIM.

Minimal sedation and daily sedation holds as per VAP prevention strategies and staffing levels allow (64). This will allow early identification of the return of consciousness in poisoned patients who can then be weaned from the ventilator.
Time Point

Within minutes after nerve agent poisoning within minutes to hours after insecticide poisoning to avoid hypoxic brain damage

Within minutes after nerve agent poisoning, within minutes to hours after insecticide poisoning to avoid hypoxic brain damage

Minutes to hours

Hours to days

For the duration of ICU stay; days to weeks As required for intubation and ventilation.

Hours to days

Hours to days

For the duration of ICU stay; days to weeks

$>7 \mathrm{~d}$ to weeks

For the duration of ICU stay; days to weeks

(Continued) 
Table 2. (Continued)

Intervention

Standard ICU care to improve survival of patients with ARDS

Careful observation

Extubation

Comment

Time Point

GI ulceration care, nutrition, thrombosis prophylaxis, timely antibiotics for infections, judicious intravenous fluid management and lung protective ventilation strategies (115)

Careful observation of patients with OP insecticide poisoning will identify cholinergic features, labored respiratory efforts, and proximal muscle weakness heralding the onset of IMS or delayed cholinergic effects.

Requires several hours of successful spontaneous ventilation and the ability to lift their head off the bed on at least three different time points before a trial of extubation should be attempted (96).

If prolonged ventilation is anticipated consider tracheostomy. Be aware of laryngeal muscle dysfunction.

Definition of abbreviations: ARDS = acute respiratory distress syndrome; BuChE = butyrylcholinesterase; CIP = critical illness polyneuropathy;

$\mathrm{CIM}=$ critical illness myopathy; $\mathrm{Gl}=$ gastrointestinal; ICU = intensive care unit; IMS = intermediate syndrome; NDMRs = nondepolarizing muscle relaxants; $\mathrm{NMBA}=$ neuromuscular blocking agent; $\mathrm{OP}=$ organophosphate; VAP = ventilator-associated pneumonia.

standard atropine dosing (2-5 mg every 10-15 min) (94). No clinical studies have been performed after OP nerve agent poisoning, but this titrated regimen can be followed for patients who survive to hospital presentation (95).

Airway control is vital to reduce the risk of complications, supporting the need for early intubation and mechanical ventilation. Because of recurrent cholinergic toxicity and NMJ dysfunction, it is important to regularly and carefully monitor poisoned patients to identify those who require intubation, extubation, or potential tracheostomy.

Simple signs of respiratory distress include increased respiratory rate, sweating, reduced minute/tidal volume, and/or FVC. A patient unable to lift his head off the pillow is a good marker of someone who will likely require intubation or who will fail extubation (alongside other standard extubation criteria [96]). In a western ICU, 12 of 33 OP-poisoned patients suffered from extubation failure, and two patients (6\%) required tracheostomy for prolonged ventilation (53).

The role of oximes is controversial. These drugs reactivate OP-inhibited $\mathrm{AChE}$ and therefore counter nicotinic and muscarinic effects, complementing atropine. A recent Cochrane review suggested that there is insufficient evidence to determine whether oximes are beneficial or harmful in OP insecticide poisoning (10). Oximes clearly reactivate AChE inhibited by some OP nerve agents or OP insecticides (97), but the effect is variable depending on the oxime, the OP involved, the dose of OP, and the delay to treatment, and the clinical benefit elicited by this AChE reactivation is unproven. One randomized control trial suggests that early $(<2 \mathrm{~h})$ high-dose use of oximes with insecticide poisoning may be beneficial (98), but other trials have not been able to demonstrate a benefit in terms of improved mortality or duration of ventilation or hospital stay (10).

Current guidelines suggest giving a bolus dose followed by an infusion (Table 2). Efficacy should be monitored using electrophysiology. The optimal duration of infusion is uncertain, but there is a lack of evidence for benefit after 2 days unless there is clear deterioration when oximes are stopped. The use of oximes for nerve agent poisoning has generally involved prehospital administration with pralidoxime, obidoxime, or HI-6 autoinjectors, together with atropine. If auto-injectors are not available, a standard dose of oxime should be administered as soon as possible.
For the duration of ICU stay; days to weeks

Hours to days after poisoning and after extubation

Hours to days

\section{Potential Therapies}

Treatment for OP poisoning has changed little since atropine and oximes were first used in the 1950s $(99,100)$, despite many thousands of animal studies. Muscarinic effects are countered with atropine and nicotinic effects countered with oximes, whereas diazepam is given for seizures and agitation. This approach is not highly effective, with many patients dying despite recently improved atropine dosing regimens and critical care.

Because the main side effects of excess atropine are confusion and agitation, use of the peripheral muscarinic antagonist glycopyrrolate has been proposed (101). However, atropine's side effects can be reduced by careful titration against effect. In addition, because OPs penetrate into the CNS, it is essential that antimuscarinic drugs enter the CNS. Major efforts are ongoing to identify novel oximes that might work in combination for a range of OPs (especially nerve agents) or that might reactivate aged $\mathrm{AChE}$, which does not usually respond to oximes (102).

Researchers have suggested that nicotinic receptor blockade with NMJ blocking agents (neuromuscular blocking agents) could be added to atropine to prevent nicotinic overstimulation and NMJ 
dysfunction, potentially shortening the duration of ventilation (102). Careful clinical studies of neuromuscular blocking agents are needed in patients being intubated for acute cholinergic toxicity and ventilation.

Parenteral or aerosolized human or recombinant $\mathrm{BuChE}$ are undergoing preclinical testing (104). Because BuChE is a stoichiometric inhibitor of OP compounds, coadministration of oximes may allow reactivation of inhibited $\mathrm{BuChE}$ and repeated effects. However, FFP (containing BuChE) has yet to show a benefit in human OP insecticide poisoning $(105,106)$, indicating that very large doses of $\mathrm{BuChE}$ may be required to neutralize lethal doses of moderately potent $\mathrm{OP}$ insecticides. Therefore, the approach may only benefit patients poisoned by highly potent OP nerve agents and insecticides.
Other novel therapies include OP hydrolases, glutamate antagonists, adenosine, $\alpha-2$ agonists, and intralipid (104, 107-110). Sodium bicarbonate, magnesium, and diazepam are used in human OP insecticide poisonings but have not shown overall benefit $(107,111)$. Improved airway control during hospital transfer, by intubation or placement of supraglottic airways, could reduce pulmonary complications.

\section{Conclusions}

$\mathrm{OP}$ insecticide poisoning is a major global method of suicide; OP nerve agents have the potential to kill large numbers of people. Both OP types kill primarily by causing respiratory failure and its complications; therefore, prompt resuscitation is essential to reduce morbidity and mortality. Early atropinization combined with good critical care and careful observation for recurrent cholinergic toxicity and development of NMJ dysfunction will save thousands of lives each year. However, research is currently poorly coordinated. Large numbers of animal studies have not resulted in improvements in clinical care. There is an urgent need for more detailed clinical studies of poisoned patients and for better communication between clinical and preclinical scientists if research is to result in improved medical care for OP-poisoned patients.

Author disclosures are available with the text of this article at www.atsjournals.org.

Acknowledgment: The authors thank Nick Buckley for his critical comments.

\section{References}

1. WHO. Public health impact of pesticides used in agriculture. Geneva, Switzerland: World Health Organization; 1990.

2. Gunnell D, Eddleston M, Phillips MR, Konradsen F. The global distribution of fatal pesticide self-poisoning: systematic review. BMC Public Health 2007;7:357.

3. Patel V, Ramasundarahettige C, Vijayakumar L, Thakur JS, Gajalakshmi V, Gururaj G, Suraweera W, Jha P; Million Death Study Collaborators. Suicide mortality in India: a nationally representative survey. Lancet 2012;379:2343-2351.

4. Eddleston M. Patterns and problems of deliberate self-poisoning in the developing world. QJM 2000;93:715-731.

5. Sellestrom A, Cairns S, Barbeschi M. United nations mission to investigate allegations of the use of chemical weapons in the Syrian Arab Republic. Report on the alleged use of chemical weapons in the Ghouta area of Damascus on 21 August 2013. Geneva, Switzerland: United Nations; 2013.

6. Sidell F, Newmark J, McDonough J. Nerve agents. In: Lenhart M, editor. Medical aspects of chemical warfare. Washington, DC: Borden Institute, Walter Reed Army Medical Centre, Office of the Surgeon General, Department of the Army; 2008. pp. 155-220.

7. True B-L, Dreisbach RH. Cholinesterase inhibitor pesticides. In: True B.-L., Dreisbach RH, editors. Dreisbach's handbook of poisoning: prevention, diagnosis and treatment, 13th ed. London, UK: Parthenon; 2001. pp. 123-132.

8. Lotti M. Clinical toxicology of anticholinesterase agents in humans. Handb Pesticide Toxicol 2001;2:1043-1085.

9. Nachmansohn D, Feld EA. Studies on cholinesterase; on the mechanism of diisopropyl fluorophosphate action in vivo. J Biol Chem 1947;171:715-724.

10. Buckley NA, Eddleston M, Li Y, Bevan M, Robertson J. Oximes for acute organophosphate pesticide poisoning. Cochrane Database Syst Rev 2011:CD005085.

11. Casida JE, Quistad GB. Organophosphate toxicology: safety aspects of nonacetylcholinesterase secondary targets. Chem Res Toxicol 2004;17:983-998.

12. Duysen EG, Li B, Xie W, Schopfer LM, Anderson RS, Broomfield $\mathrm{CA}$, Lockridge $\mathrm{O}$. Evidence for nonacetylcholinesterase targets of organophosphorus nerve agent: supersensitivity of acetylcholinesterase knockout mouse to VX lethality. J Pharmacol Exp Ther 2001;299:528-535.

13. Dorandeu F, Mikler JR, Thiermann H, Tenn C, Davidson C, Sawyer TW, Lallement G, Worek F. Swine models in the design of more effective medical countermeasures against organophosphorus poisoning. Toxicology 2007;233:128-144

14. Okumura T, Takasu N, Ishimatsu S, Miyanoki S, Mitsuhashi A, Kumada K, Tanaka K, Hinohara S. Report on 640 victims of the Tokyo subway sarin attack. Ann Emerg Med 1996;28:129-135.

15. Tsao TCY, Juang YC, Lan RS, Shieh WB, Lee CH. Respiratory failure of acute organophosphate and carbamate poisoning. Chest 1990;98: 631-636.

16. Sidell FR. Soman and sarin: clinical manifestations and treatment of accidental poisoning by organophosphates. Clin Toxicol 1974;7: $1-17$

17. Lokan R, James R. Rapid death by mevinphos poisoning while under observation. Forensic Sci Int 1983;22:179-182.

18. Eyer F, Meischner V, Kiderlen D, Thiermann H, Worek F, Haberkorn M, Felgenhauer N, Zilker T, Eyer P. Human parathion poisoning. A toxicokinetic analysis. Toxicol Rev 2003;22:143-163.

19. Eddleston M, Mohamed F, Davies JOJ, Eyer P, Worek F, Sheriff MHR, Buckley NA. Respiratory failure in acute organophosphorus pesticide self-poisoning. QJM 2006;99:513-522.

20. Eddleston M, Eyer P, Worek F, Mohamed F, Senarathna L, von Meyer L, Juszczak E, Hittarage A, Azhar S, Dissanayake W, et al. Differences between organophosphorus insecticides in human self-poisoning: a prospective cohort study. Lancet 2005;366: 1452-1459.

21. Senarathna L. How the level of resources and hospital staff attitude in primary care hospitals in rural Sri Lanka affect poisoning patient outcome. Centre for Clinical Epidemiology and Biostatistics. Newcastle, Australia: University of Newcastle; 2006. pp. 1-89.

22. Wadia RS, Sadagopan C, Amin RB, Sardesai HV. Neurological manifestations of organophosphorous insecticide poisoning. J Neurol Neurosurg Psychiatry 1974;37:841-847.

23. Jayawardane P, Senanayake N, Buckley NA, Dawson AH. Electrophysiological correlates of respiratory failure in acute organophosphate poisoning: evidence for differential roles of muscarinic and nicotinic stimulation. Clin Toxicol (Phila) 2012;50: 250-253.

24. Karalliedde L, Senanayake N. Organophosphorus insecticide poisoning. Br J Anaesth 1989;63:736-750.

25. Karalliedde L. Organophosphorus poisoning and anaesthesia. Anaesthesia 1999;54:1073-1088.

26. Rezk PE, Graham JR, Moran TS, Gordon RK, Sciuto AM, Doctor BP, Nambiar MP. Acute toxic effects of nerve agent VX on respiratory 
dynamics and functions following microinsillation inhalation exposure in guinea pigs. Inhal Toxicol 2007;19:291-302.

27. Segura P, Chávez J, Montaño LM, Vargas MH, Delaunois A, Carbajal V, Gustin P. Identification of mechanisms involved in the acute airway toxicity induced by parathion. Naunyn Schmiedebergs Arch Pharmacol 1999;360:699-710.

28. Wess J, Eglen RM, Gautam D. Muscarinic acetylcholine receptors: mutant mice provide new insights for drug development. Nat Rev Drug Discov 2007;6:721-733.

29. Kamat SR, Heera S, Potdar PV, Shah SV, Bhambure NM, Mahashur AA. Bombay experience in intensive respiratory care over 6 years. J Postgrad Med 1989;35:123-134.

30. Kummer W, Lips KS, Pfeil U. The epithelial cholinergic system of the airways. Histochem Cell Biol 2008;130:219-234.

31. Takemura $Y$, Helms MN, Eaton AF, Self J, Ramosevac S, Jain L, Bao $\mathrm{H}-\mathrm{F}$, Eaton DC. Cholinergic regulation of epithelial sodium channels in rat alveolar type 2 epithelial cells. Am J Physiol Lung Cell Mol Physiol 2013;304:L428-L437.

32. Matthay MA, Folkesson HG, Clerici C. Lung epithelial fluid transport and the resolution of pulmonary edema. Physiol Rev 2002;82: $569-600$.

33. Carey JL, Dunn C, Gaspari RJ. Central respiratory failure during acute organophosphate poisoning. Respir Physiol Neurobiol 2013;189: 403-410.

34. Ware LB, Matthay MA. Alveolar fluid clearance is impaired in the majority of patients with acute lung injury and the acute respiratory distress syndrome. Am J Respir Crit Care Med 2001;163: 1376-1383.

35. Lainee P, Robineau P, Guittin P, Coq H, Benchetrit G. Mechanisms of pulmonary edema induced by an organophosphorus compound in anesthetized dogs. Fundam Appl Toxicol 1991;17:177-185.

36. Delaunois A, Gustin P, Ansay M. Multiple muscarinic receptor subtypes mediating pulmonary oedema in the rabbit. Pulm Pharmacol 1994;7: 185-193.

37. Yavuz Y, Kaya E, Yurumez Y, Sahin O, Bas O, Fidan H, Sezer M. Technetium-99m diethylenetriaminepentaacetic acid radioaerosol scintigraphy in organophosphate induced pulmonary toxicity: experimental study. Clin Toxicol (Phila) 2008;46:711-715.

38. Hulse E, Reed FC, Eddleston M, Etherington R, Clutton RE. A model describing the use of a bronchial blocking device and a sheathed bronchoscope for pulmonary aspiration studies in the Gottingen minipig. Lab Anim 2014;48:164-169.

39. Akgur S, Veral A, Ege B. Adult respiratory distress syndrome in human organophosphate poisoning cases. Toxicol Environ Chem 2008;90: 493-499.

40. Ferguson ND, Frutos-Vivar F, Esteban A, Fernández-Segoviano $P$, Aramburu JA, Nájera L, Stewart TE. Acute respiratory distress syndrome: underrecognition by clinicians and diagnostic accuracy of three clinical definitions. Crit Care Med 2005;33: 2228-2234.

41. Wright BS, Rezk PE, Graham JR, Steele KE, Gordon RK, Sciuto AM, Nambiar MP. Acute lung injury following inhalation exposure to nerve agent VX in guinea pigs. Inhal Toxicol 2006;18:437-448.

42. Perkins MW, Wong B, Rodriguez A, Devorak JL, Alves DA, Murphy G, Sciuto AM. Inhalation toxicity of soman vapor in non-anesthetized rats: a preliminary assessment of inhaled bronchodilator or steroid therapy. Chem Biol Interact 2013;206:452-461.

43. Gundavarapu S, Zhuang J, Barrett EG, Xu F, Russell RG, Sopori ML. A critical role of acute bronchoconstriction in the mortality associated with high-dose sarin inhalation: effects of epinephrine and oxygen therapies. Toxicol Appl Pharmacol 2014;274:200-208.

44. Anzueto A, deLemos RA, Seidenfeld J, Moore G, Hamil H, Johnson D, Jenkinson SG. Acute inhalation toxicity of soman and sarin in baboons. Fundam Appl Toxicol 1990;14:676-687.

45. De Candole CA, Douglas WW, Evans CL, Holmes R, Spencer KEV, Torrance RW, Wilson KM. The failure of respiration in death by anticholinesterase poisoning. Br Pharmacol Chemother 1953;8: 466-475.

46. Singh G, Sidhu UPS, Mahajan R, Avasthi G, Whig J. Phrenic nerve conduction studies in acute organophosphate poisoning. Muscle Nerve 2000;23:627-632.
47. Gaspari RJ, Paydarfar D. Dichlorvos-induced central apnea: effects of selective brainstem exposure in the rat. Neurotoxicology 2011;32: 206-214.

48. Burchfiel JL, Duffy FH. Organophosphate neurotoxicity: chronic effects of sarin on the electroencephalogram of monkey and man. Neurobehav Toxicol Teratol 1982;4:767-778.

49. Bird SB, Gaspari RJ, Dickson EW. Early death due to severe organophosphate poisoning is a centrally mediated process. Acad Emerg Med 2003;10:295-298.

50. Dickson EW, Bird SB, Gaspari RJ, Boyer EW, Ferris CF. Diazepam inhibits organophosphate-induced central respiratory depression. Acad Emerg Med 2003;10:1303-1306.

51. Banks CN, Lein PJ. A review of experimental evidence linking neurotoxic organophosphorus compounds and inflammation. Neurotoxicology 2012;33:575-584.

52. John M, Oommen A, Zachariah A. Muscle injury in organophosphorous poisoning and its role in the development of intermediate syndrome. Neurotoxicology 2003;24:43-53.

53. Hrabetz H, Thiermann H, Felgenhauer N, Zilker T, Haller B, Nährig J, Saugel B, Eyer F. Organophosphate poisoning in the developed world - a single centre experience from here to the millennium. Chem Biol Interact 2013;206:561-568.

54. Eddleston M, Haggalla S, Reginald K, Sudarshan K, Senthilkumaran M, Karalliedde L, Ariaratnam A, Sheriff MHR, Warrell DA, Buckley NA. The hazards of gastric lavage for intentional selfpoisoning in a resource poor location. Clin Toxicol (Phila) 2007; 45:136-143.

55. Isbister GK, Downes F, Sibbritt D, Dawson AH, Whyte IM. Aspiration pneumonitis in an overdose population: frequency, predictors, and outcomes. Crit Care Med 2004;32:88-93.

56. Schubert ML, Peura DA. Control of gastric acid secretion in health and disease. Gastroenterology 2008;134:1842-1860.

57. Aihara T, Nakamura Y, Taketo MM, Matsui M, Okabe S. Cholinergically stimulated gastric acid secretion is mediated by $M(3)$ and $M(5)$ but not $M(1)$ muscarinic acetylcholine receptors in mice. Am J Physiol Gastrointest Liver Physiol 2005;288: G1199-G1207.

58. Marik PE. Aspiration pneumonitis and aspiration pneumonia. N Engl J Med 2001;344:665-671.

59. Brégeon F, Papazian L, Delpierre S, Kajikawa O, Payan M-J, Martin TR, Kipson N, Pugin J. Role of proinflammatory activity contained in gastric juice from intensive care unit patients to induce lung injury in a rabbit aspiration model. Crit Care Med 2008;36: 3205-3212.

60. Meade MO, Cook DJ, Guyatt GH, Slutsky AS, Arabi YM, Cooper DJ, Davies AR, Hand LE, Zhou Q, Thabane L, et al.; Lung Open Ventilation Study Investigators. Ventilation strategy using low tidal volumes, recruitment maneuvers, and high positive endexpiratory pressure for acute lung injury and acute respiratory distress syndrome: a randomized controlled trial. JAMA 2008; 299:637-645.

61. Matthay MA, Rosen GD. Acid aspiration induced lung injury. New insights and therapeutic options. Am J Respir Crit Care Med 1996; 154:277-278.

62. Chawla R. Epidemiology, etiology, and diagnosis of hospital-acquired pneumonia and ventilator-associated pneumonia in Asian countries. Am J Infect Control 2008; 36(4, Suppl)S93-S100.

63. Slutsky AS, Ranieri VM. Ventilator-induced lung injury. N Engl J Med 2013;369:2126-2136.

64. Hunter JD. Ventilator associated pneumonia. BMJ 2012;344:e3325.

65. Walsh TS, Morris AC, Simpson AJ. Ventilator associated pneumonia: can we ensure that a quality indicator does not become a game of chance? Br J Anaesth 2013;111:333-337.

66. Price R, MacLennan G, Glen J; SuDDICU Collaboration. Selective digestive or oropharyngeal decontamination and topical oropharyngeal chlorhexidine for prevention of death in general intensive care: systematic review and network meta-analysis. BMJ 2014;348:g2197.

67. Tracey KJ. Physiology and immunology of the cholinergic antiinflammatory pathway. J Clin Invest 2007;117:289-296.

68. Wang H, Yu M, Ochani M, Amella CA, Tanovic M, Susarla S, Li JH, Wang $\mathrm{H}$, Yang $\mathrm{H}$, Ulloa L, et al. Nicotinic acetylcholine receptor 
alpha7 subunit is an essential regulator of inflammation. Nature 2003; 421:384-388.

69. Giebelen IAJ, Leendertse M, Florquin S, van der Poll T. Stimulation of acetylcholine receptors impairs host defence during pneumococcal pneumonia. Eur Respir J 2009;33:375-381.

70. Xu M, Scott JE, Liu K-Z, Bishop HR, Renaud DE, Palmer RM, SoussiGounni A, Scott DA. The influence of nicotine on granulocytic differentiation - inhibition of the oxidative burst and bacterial killing and increased matrix metalloproteinase- 9 release. $B M C$ Cell Biol 2008;9:19.

71. Zabrodskii PF, Grishin VA, Borodavko VK. Mechanism of suppression of phagocytic and metabolic activity of neutrophils and production of proinflammatory cytokines during chronic poisoning with organophosphorus compounds. Bull Exp Biol Med 2013;155: 464-466.

72. Gwilt CR, Donnelly LE, Rogers DF. The non-neuronal cholinergic system in the airways: an unappreciated regulatory role in pulmonary inflammation? Pharmacol Ther 2007;115:208-222.

73. Hermanowicz A, Kossman S. Neutrophil function and infectious disease in workers occupationally exposed to phosphoorganic pesticides: role of mononuclear-derived chemotactic factor for neutrophils. Clin Immunol Immunopathol 1984;33:13-22.

74. Senanayake N, Karalliedde L. Neurotoxic effects of organophosphorus insecticides. An intermediate syndrome. N Engl J Med 1987;316: 761-763.

75. Indira M, Andrews MA, Rakesh TP. Incidence, predictors, and outcome of intermediate syndrome in cholinergic insecticide poisoning: a prospective observational cohort study. Clin Toxicol (Phila) 2013; 51:838-845.

76. De Bleecker J, Van den Neucker K, Colardyn F. Intermediate syndrome in organophosphorus poisoning: a prospective study. Crit Care Med 1993;21:1706-1711.

77. Jayawardane P, Dawson AH, Weerasinghe V, Karalliedde L, Buckley NA, Senanayake N. The spectrum of intermediate syndrome following acute organophosphate poisoning: a prospective cohort study from Sri Lanka. PLoS Med 2008;5:1143-1153.

78. Sidell FR, Hurst CG. Chapter 8: Long-term health effects of nerve agents and mustard. In: Sidell FR, Takafuji ET, Franz DR, editors. Medical aspects of chemical and biological warfare. Washington, DC: U.S. Government Printing; 1997. pp. 229-246.

79. Morita H, Yanagisawa N, Nakajima T, Shimizu M, Hirabayashi H, Okudera H, Nohara M, Midorikawa Y, Mimura S. Sarin poisoning in Matsumoto, Japan. Lancet 1995;346:290-293.

80. Khan S, Hemalatha R, Jeyaseelan L, Oommen A, Zachariah A. Neuroparalysis and oxime efficacy in organophosphate poisoning: a study of butyrylcholinesterase. Hum Exp Toxicol 2001;20:169-174.

81. Eddleston M, Street JM, Self I, Thompson A, King T, Williams N, Naredo G, Dissanayake K, Yu L-M, Worek F, et al. A role for solvents in the toxicity of agricultural organophosphorus pesticides. Toxicology 2012;294:94-103.

82. De Reuck J, Willems J. Acute parathion poisoning: myopathic changes in the diaphragm. $J$ Neurol 1975;208:309-313.

83. Davies JE, Barquet A, Freed VH, Haque R, Morgade C, Sonneborn RE, Vaclavek $C$. Human pesticide poisonings by a fat-soluble organophosphate insecticide. Arch Environ Health 1975;30: 608-613.

84. Peter JV, Prabhakar AT, Pichamuthu K. Delayed-onset encephalopathy and coma in acute organophosphate poisoning in humans. Neurotoxicology 2008;29:335-342.

85. Glynn P. A mechanism for organophosphate-induced delayed neuropathy. Toxicol Lett 2006;162:94-97.

86. Richardson RJ, Hein ND, Wijeyesakere SJ, Fink JK, Makhaeva GF. Neuropathy target esterase (NTE): overview and future. Chem Biol Interact 2013;203:238-244.

87. Rivett K, Potgieter PD. Diaphragmatic paralysis after organophosphate poisoning. A case report. S Afr Med J 1987;72:881-882.

88. Yanagisawa N, Morita H, Nakajima T. Sarin experiences in Japan: acute toxicity and long-term effects. J Neurol Sci 2006; 249:76-85.
89. Ghanei M, Naderi M, Kosar AM, Harandi AA, Hopkinson NS, Poursaleh Z. Long-term pulmonary complications of chemical warfare agent exposure in Iraqi Kurdish civilians. Inhal Toxicol 2010;22:719-724

90. Nogué S, Sanz P, Borondo JC, Picón M, de la Red G, Mestre G. Fatal lipoid pneumonia due to bronco-aspiration of isoparaffin after ingestion of an organophosphate insecticide. Acta Anaesthesiol Scand 2003;47:777-779.

91. Eddleston M, Dawson A, Karalliedde L, Dissanayake W, Hittarage A, Azher S, Buckley NA. Early management after self-poisoning with an organophosphorus or carbamate pesticide - a treatment protocol for junior doctors. Crit Care 2004;8:R391-R397.

92. Konickx LA, Bingham K, Eddleston M. Is oxygen required before atropine administration in organophosphorus or carbamate pesticide poisoning? - A cohort study. Clin Toxicol (Phila) 2014;52: 531-537.

93. Eddleston M, Buckley NA, Checketts H, Senarathna L, Mohamed F, Sheriff MHR, Dawson A. Speed of initial atropinisation in significant organophosphorus pesticide poisoning-a systematic comparison of recommended regimens. J Toxicol Clin Toxicol 2004;42:865-875.

94. Abedin MJ, Sayeed AA, Basher A, Maude RJ, Hoque G, Faiz MA. Open-label randomized clinical trial of atropine bolus injection versus incremental boluses plus infusion for organophosphate poisoning in Bangladesh. J Med Toxicol 2012;8:108-117.

95. Thiermann $\mathrm{H}$, Worek F, Kehe K. Limitations and challenges in treatment of acute chemical warfare agent poisoning. Chem Biol Interact 2013; 206:435-443.

96. Maclntyre NR, Cook DJ, Ely EW Jr, Epstein SK, Fink JB, Heffner JE, Hess D, Hubmayer RD, Scheinhorn DJ; American College of Chest Physicians; American Association for Respiratory Care; American College of Critical Care Medicine. Evidence-based guidelines for weaning and discontinuing ventilatory support: a collective task force facilitated by the American College of Chest Physicians; the American Association for Respiratory Care; and the American College of Critical Care Medicine. Chest 2001; 120(6, Suppl)375S-395S.

97. Worek F, Thiermann H, Szinicz L, Eyer P. Kinetic analysis of interactions between human acetylcholinesterase, structurally different organophosphorus compounds and oximes. Biochem Pharmacol 2004;68:2237-2248.

98. Pawar KS, Bhoite RR, Pillay CP, Chavan SC, Malshikare DS, Garad SG. Continuous pralidoxime infusion versus repeated bolus injection to treat organophosphorus pesticide poisoning: a randomised controlled trial. Lancet 2006;368:2136-2141.

99. Namba T, Nolte CT, Jackrel J, Grob D. Poisoning due to organophosphate insecticides. Acute and chronic manifestations. Am J Med 1971;50:475-492.

100. Grob $D$. The manifestations and treatment of poisoning due to nerve gas and other organic phosphate anticholinesterase compounds. AMA Arch Intern Med 1956;98:221-239.

101. Bardin PG, Van Eeden SF. Organophosphate poisoning: grading the severity and comparing treatment between atropine and glycopyrrolate. Crit Care Med 1990;18:956-960.

102. Elsinghorst PW, Worek F, Thiermann H, Wille T. Drug development for the management of organophosphorus poisoning. Expert Opin Drug Discov 2013;8:1467-1477.

103. Sheridan RD, Smith AP, Turner SR, Tattersall JE. Nicotinic antagonists in the treatment of nerve agent intoxication. $J$ R Soc Med 2005;98: 114-115.

104. Rosenberg YJ, Laube B, Mao L, Jiang X, Hernandez-Abanto S, Lee $\mathrm{KD}$, Adams R. Pulmonary delivery of an aerosolized recombinant human butyrylcholinesterase pretreatment protects against aerosolized paraoxon in macaques. Chem Biol Interact 2013;203: 167-171.

105. Pichamuthu K, Jerobin J, Nair A, John G, Kamalesh J, Thomas K, Jose A, Fleming JJ, Zachariah A, David SS, et al. Bioscavenger therapy for organophosphate poisoning - an open-labeled pilot randomized trial comparing fresh frozen plasma or albumin with saline in acute organophosphate poisoning in humans. Clin Toxicol (Phila) 2010;48:813-819.

106. Pazooki S, Solhi H, Vishteh HR, Shadnia S, Beigi MJ. Effectiveness of fresh frozen plasma as supplementary treatment in organophosphate poisoning. Med J Malaysia 2011;66:342-345. 
107. Buckley NA, Eddleston M, Dawson AH. The need for translational research on antidotes for pesticide poisoning. Clin Exp Pharmacol Physiol 2005;32:999-1005.

108. Peter JV, Moran JL, Pichamuthu K, Chacko B. Adjuncts and alternatives to oxime therapy in organophosphate poisoning-is there evidence of benefit in human poisoning? A review. Anaesth Intensive Care 2008;36:339-350.

109. Dunn C, Bird SB, Gaspari R. Intralipid fat emulsion decreases respiratory failure in a rat model of parathion exposure. Acad Emerg Med 2012;19:504-509.

110. Gupta RD, Goldsmith M, Ashani Y, Simo Y, Mullokandov G, Bar H, Ben-David M, Leader H, Margalit R, Silman I, et al. Directed evolution of hydrolases for prevention of G-type nerve agent intoxication. Nat Chem Biol 2011;7: 120-125.

111. Basher A, Rahman SH, Ghose A, Arif SM, Faiz MA, Dawson $\mathrm{AH}$. Phase II study of magnesium sulfate in acute organophosphate pesticide poisoning. Clin Toxicol (Phila) 2013;51:35-40.

112. Fleming NW, Macres S, Antognini JF, Vengco J. Neuromuscular blocking action of suxamethonium after antagonism of vecuronium by edrophonium, pyridostigmine or neostigmine. Br J Anaesth 1996;77:492-495.

113. Sener EB, Ustun E, Kocamanoglu S, Tur A. Prolonged apnea following succinylcholine administration in undiagnosed acute organophosphate poisoning. Acta Anaesthesiol Scand 2002;46: 1046-1048.

114. Baruah J, Easby J, Kessell G. Effects of acetylcholinesterase inhibitor therapy for Alzheimer's disease on neuromuscular block. Br J Anaesth 2008;100:420.

115. Erickson SE, Martin GS, Davis JL, Matthay MA, Eisner MD, NIH NHLBI ARDS Network. Recent trends in acute lung injury mortality: 19962005. Crit Care Med 2009;37:1574-1579. 